\title{
Photosynthesis by six Portuguese maize cultivars during drought stress and recovery
}

Ricardo Cruz de Carvalho ${ }^{1, *}$, Ana Cunha ${ }^{2}$, Jorge Marques da Silva ${ }^{1}$

${ }^{1}$ Centre for Biodiversity, Functional and Integrative Genomics (BioFIG) and Departamento de Biologia Vegetal da Faculdade de Ciências da Universidade de Lisboa, Campo Grande, 1749-016 Lisboa, Portugal

${ }^{2}$ Centre for the Research and Technology of Agro-environmental and Biological Sciences (CITAB) and Departamento de Biologia, Escola de Ciências da Universidade do Minho, Campus de Gualtar, 4710-057 Braga, Portugal

* Corresponding author. Email: rfcruz@fc.ul.pt. Tel.: +351 217500000 (ext. 21148). Fax: +351 217500048

\begin{abstract}
Photosynthesis, chlorophyll fluorescence and leaf water parameters were measured in six Portuguese maize (Zea mays L.) cultivars during and following a period of drought stress. The leaf relative water content (RWC) responded differently among cultivars but, except for cultivar PB369, recovered close to initial values after watering was restored. Photosynthetic rate and stomatal conductance decreased with drought but more slowly in cultivars PB269 and PB260 than in cultivars AD3R, PB64, PB304 and PB369. Water use efficiency (WUE) decreased during the water stress treatment although with cultivar PB260 the decrease was marked only when the RWC fell below 40\%. Recovery of WUE was seen with all cultivars except PB369. The maximum quantum efficiency of photosystem II, the photochemical quenching coefficient, the electron transport rate in PSII and the estimated functional plastoquinone pool tended to decrease with drought, while the non-photochemical quenching coefficient increased. The parameters estimated from chlorophyll fluorescence did not recover in PB369, during re-watering. The results show that PB260 and PB269 were the most tolerant and PB369 was the least tolerant cultivars to water stress. The variation found amongst the cultivars tested suggests the existence of valuable genetic resources for crop improvement in relation to drought tolerance.
\end{abstract}

Keywords: maize, drought, recovery, Chl $a$ fluorescence, gas-exchange

Abbreviations: A, photosynthetic rate; $\mathrm{C}_{\mathrm{i}}$, intercellular $\mathrm{CO}_{2}$ partial pressure; Chl, chlorophyll; d.f., degrees of freedom; E, transpiration rate; ETR, electron transport rate on PSII; $F_{v} / F_{m}$, maximum quantum efficiency of PSII; $g_{s}$, stomatal conductance; IRGA, infrared gas analysis; PPFD, photosynthetic photon flux density; PSI (II), photosystem I (II); PQ, plastoquinone; qN, non-photochemical quenching coefficient; qP, photochemical quenching coefficient; $\mathrm{RH}$, relative humidity; RWC, leaf relative water content; $\mathrm{S}_{\mathrm{m}}$, estimated functional plastoquinone pool; WUE, water use efficiency. 


\section{Introduction}

Water availability on land varies geographically and locally because of the uneven distribution and unpredictability of rainfall. Climate changes and population growth will cause more frequent shortages of water for agriculture, industry and domestic use. Water is essential both physically and biochemically for plants, and strategies for its efficient use and for improved drought tolerance are of paramount importance.

During their life cycle plants may experience frequent periods of water deficit even outside arid and semi-arid areas, for example in temperate deciduous forests (Burghardt and Riederer 2003) and in tropical forests (Asner et al. 2004). Some differences found between species with respect to growth and survival can be attributed more to different abilities for water acquisition, transport and conservation, than to differences in metabolism. However, the regulation of photosynthetic metabolism is also dependent on processes that can be affected by water stress, such as $\mathrm{CO}_{2}$ diffusion into the leaf, allocation of carbon to non-photosynthetic organs, the production of osmoprotectants and several aspects of leaf biochemistry (Chaves et al. 2002). Early responses to water stress can be seen as a first line of defense allowing survival in a short time scale. To survive more persistent stress periods, plants need to undergo an acclimation process (Sharp et al. 2004) resulting in changes in metabolism and/or structure mediated by changes in regulation of gene expression. Physiological responses to environmental stress have to be activated to prevent serious tissue damage (Hare et al. 1999).

In $\mathrm{C}_{3}$ plants, the gradual implementation of moderate water deficits leads almost exclusively to decreased stomatal conductance (Cornic and Fresneau 2002). As water deficit increases, stomata close in response to a decreased turgor and/or leaf water potential (Yordanov et al. 2003), or to an increase in ABA concentration in the transpiration stream (Sharp and LeNoble 2002; Pospíšilová 2003). Stomatal closure limits dehydration and decreases the risk of xylem cavitation, which could compromise plant survival.

Studies concerning the effect of water stress on the photosynthesis by $C_{4}$ plants are fewer than for $C_{3}$ (Ghannoum 2009), despite their ecological, social and economic relevance. $\mathrm{C}_{4}$ plants evolved 50-60 million years ago (Jacobs et al. 1999; Kellogg 2001) when temperatures were higher by 8-10 ${ }^{\circ} \mathrm{C}$ and the concentration of $\mathrm{CO}_{2}$ in the atmosphere was lower than at present. They thrive nowadays in arid and semi-arid environments (Edwards and Still 2008) and rank amongst the most productive species. Some $7500 \mathrm{C}_{4}$ species account for $23 \%$ of the primary productivity in the terrestrial biosphere (Still et al. 2003), and constitute major food and forage resources worldwide. Additionally, with an increasing world population imposing higher demands for plant biomass, and the predictions that climate changes will decrease the availability of water in several geographic regions, $\mathrm{C}_{4}$ plants appear as natural candidates for increased exploitation in agriculture. $\mathrm{C}_{4}$ plants can maintain photosynthetic activity (Bruce et al. 2002; Carmo-Silva et al. 2007) and root and shoot growth (Siddique et al. 1999; Nayyar 2003) at water potentials that are inhibitory for most $\mathrm{C}_{3}$ plants, and have higher stomatal resistances and water use efficiencies (WUE) than their $\mathrm{C}_{3}$ counterparts. Furthermore, $\mathrm{C}_{4}$ species of the NAD-Malic Enzyme (NAD-ME) type show better WUE than NADPMalic Enzyme (NADP-ME) species such as maize (Ghannoum et al. 2002). However, it is still a matter of dispute if $\mathrm{C}_{4}$ plants are more resistant to water stress (Ghannoum 2009).

Maize and sugarcane are the two most important $C_{4}$ crops (Beerling 2007). Maize is widely cultivated throughout the world and a greater weight of maize is produced each year than any other grain. Most of the world production is from hybrid maize, but there is a limit to hybrid maize breeding in the identification and abundance of suitable genotypes for generating heterosis (Hadi 2007). Due to this limitation, there is a growing interest in local cultivars as a source of genetic variability. 
Maize has been grown for four centuries in Portugal. Until the 1980’s, farmers selected mainly open pollinated varieties in order to maintain genetic diversity and increase the adaptability of the landraces to a large variety of edaphic and climatic conditions (Pêgo 1997). Microsatellite-based studies have already shown that there is high genetic diversity among the resulting Portuguese cultivars (Vaz Patto et al. 2004) but physiological studies to evaluate the variability of the response to water stress are scarce.

Non-invasive techniques were used to evaluate the effects of water stress on photosynthesis by six maize cultivars selected for likely contrasting water stress responses based partly on a screen for genetic diversity (Vaz Patto et al. 2004). Physiological variability will be useful for the selection of drought tolerant traits/cultivars and will contribute to the understanding of water stress effects and responses in $\mathrm{C}_{4}$ plants.

\section{Materials and methods}

Plant material, water stress/ irrigation treatment and sampling procedures

Maize seeds (homozygous cultivars AD3R, PB64, PB260, PB269, PB304, PB369) from the Portuguese Bank of Plant Germplasm (BPGV, Braga) were sterilized for $5 \mathrm{~min}$ in 10\% commercial bleach and soaked in running water for 24 h. Thereafter, they were germinated and grown for one week in the dark on sterile wet filter paper in Petri dishes, under controlled growth conditions $\left(25^{\circ} \mathrm{C}\right.$ day / $18{ }^{\circ} \mathrm{C}$ night). Seedlings of similar size were selected and placed one per pot (500 mL) in soil, with a surface fertilizer (0.3 $\mathrm{Kg} \mathrm{m}^{-2}$, NPK 10:1:1, Neorgan, Shacham Givatada Ltd., Israel). The pots were kept in a growth chamber under controlled conditions (16 h photoperiod, $25^{\circ} \mathrm{C}$ day / $18{ }^{\circ} \mathrm{C}$ night, PPFD of $400-500 \mu \mathrm{mol}$ photons $\mathrm{m}^{-2} \mathrm{~s}^{-1}$ and RH of approximately 50\%) and watered daily to field capacity (approximately $30 \%$ soil water content). Forty-five days after the onset of germination, water stress was imposed by withholding water for six days after which plants were again watered daily for further six days to evaluate the recovery response. During this experimental period of twelve days, plants were sampled every second day (day 0, 2, 4, 6, 8, 10, 12). On each sampling day, 4-5 leaves from different plants (true replicates) were used per cultivar. Physiological measurements were made on the mid segment of the last fully expanded leaf using the same replicates along the experiment. This approach was selected to reduce sampling error and to detect differences between cultivar responses.

\section{Leaf water status}

Leaf relative water content (RWC) was calculated according to Catsky (1960) in samples immediately excised from the leaves used for the photosynthetic measurements. Fresh, fully turgid and dry weights were determined with an analytical scale (BP 210D, Sartorius, Germany). Fresh weight was obtained immediately after sample excision, fully turgid weight was obtained after floating the sample in deionized water for $4 \mathrm{~h}$ and dry weight was obtained after $48 \mathrm{~h}$ at $70{ }^{\circ} \mathrm{C}$. Whenever necessary, leaf area was determined using an area meter (CI-202 Portable Leaf Area Meter, CID, Inc., Camas, Washington, USA). 
Gas exchange and stomatal conductance

Two IRGA (Infrared Gas Analyser) models were used (LCPro+ and LCA-2, ADC-The Analytical Development Co., Ltd., Hoddesdon, England). Photosynthetic (A) and transpiration (E) rates, partial pressure of $\mathrm{CO}_{2}$ in the mesophyll intercellular space $\left(\mathrm{C}_{\mathrm{i}}\right)$ and stomatal conductance $\left(\mathrm{g}_{\mathrm{s}}\right)$ were calculated using von Caemmerer and Farquhar (1981) and Long and Hallgren (1985, 1993) equations. Water use efficiency (WUE) was calculated as the ratio between photosynthetic and transpiration rates. In the LCPro+ model light was provided by a red LED array placed on top of the leaf clip, while in the LCA-2 model, the light source was provided externally by a white halogen lamp mounted in a commercial slide projector (Sawyer's 302 Automatic, Belgium). Both light sources were set to provide a photosynthetic active radiation of $870 \mu \mathrm{mol}$ photons $\mathrm{m}^{-2} \mathrm{~s}^{-1}$. Leaves were illuminated for 30 min under normal atmospheric $\mathrm{CO}_{2}$ content (approximately $370 \mathrm{ppm}$ ), a relative humidity of 50-60\% and a temperature of about $25{ }^{\circ} \mathrm{C}$.

\section{Modulated Chl a fluorescence}

Measurements of Chl $a$ fluorescence were made using a PAM 210 fluorometer (Heinz Walz GmbH, Effeltrich, Germany) controlled by DA-TEACH v1.11 software (Heinz Walz GmbH, Effeltrich, Germany), after the gas-exchange measurements using the same leaves. Leaves were placed in darkness for $5 \mathrm{~min}$. The minimal fluorescence $\left(\mathrm{F}_{\mathrm{o}}\right)$ was measured under measuring light, immediately before the application of a red saturating light pulse (3500 $\mu$ mol photons

$\left.\mathrm{m}^{-2} \mathrm{~s}^{-1}\right)$. This light pulse allowed the determination of the maximal fluorescence yield $\left(\mathrm{F}_{\mathrm{m}}\right)$ and the computation of the maximum photochemical efficiency of photosystem II (PSII) $\left(F_{v} / F_{m}\right)$. To determine the effective efficiency of PSII photochemistry $\left(\Phi_{\mathrm{PSII}}\right)$, the electron transport rate $(\mathrm{ETR})$ and both the photochemical $(\mathrm{qP})$ and non-photochemical (qN) quenching coefficients at steady-state conditions, red actinic light was provided (840 $\mu \mathrm{mol}$ photons $\left.\mathrm{m}^{-2} \mathrm{~s}^{-1}\right)$ for $30 \mathrm{~min}$, followed by a new saturating light pulse. The equation of Genty et al. (1989) was used to calculate $\Phi_{\text {PSII }}$ and ETR was given by the expression $\mathrm{ETR}=\Phi_{\mathrm{PSII}} \mathrm{x}$ PPFD $\mathrm{x} 0.5 \times 0.84$, where the factor 0.5 corresponds to the photon fraction arriving to PSII (relatively to photosystem I (PSI)), and the factor 0.84 corresponds to the fraction of incident light that is absorbed by the leaf. Quenching coefficients ( $\mathrm{qP}$ and $\mathrm{qN}$ ) were calculated as in Schreiber et al. (1986). The variation of the area above the rapid fluorescence rise curve normalized by the variable fluorescence $\left(\mathrm{S}_{\mathrm{m}}\right)$ was calculated as in Strasser et al. (2004).

\section{Statistical analyses}

The overall effect of the water treatment on leaf RWC was analysed by a two-way ANOVA followed by posthoc Bonferroni test for multiple comparisons which identifies differences between cultivars in each sampling day. To analyse the effect of water treatment on leaf RWC during the water stress/recovery cycle for each cultivar, a one-way ANOVA followed by post-hoc Tukey test was performed. Statistical results were registered following the common lettering notation: mean values with different letters were significantly different $(p<0.05)$. Relationships between variables/parameters and leaf RWC were investigated by linear and non-linear regression analyses using all empirical values (replicates). The measurements made on the $6^{\text {th }}$ day of stress were obtained immediately before re-watering and were therefore used for fitting the regression equations for both stress and stress recovery as a function of RWC. Thereby, they were considered as the last point of stress treatment and the first point, or point zero, of the recovery period. The correlation coefficients (r) obtained and the degrees of freedom (d.f.) were used to determine the levels of 
significance $(p)$ of each regression model since all models were linear in their parameters. The d.f. were determined subtracting the number of parameters estimated by each model from the total number of observations. All statistical analyses were performed with Prism v4.0 (GraphPad Software, Inc, La Jolla, U.S.A.).

\section{Results and Discussion}

\section{Relative water content}

In the first 4 days of water stress treatment, only cultivar PB260 showed a significant decrease (to circa 60\%) in RWC (Fig. 1). The RWC of PB260 leaves decreased to less than $40 \%$ at the end of the stress period (Fig. 1C), whereas the other cultivars decreased to only circa $60 \%$ on the $6^{\text {th }} \mathrm{d}$ of stress.

After re-watering, the RWC of cultivars AD3R, PB64, PB269 and PB304 recovered to the initial values, whereas in PB260 and PB369 only circa 85\% and 70\% of the RWC were recovered, respectively (Table I). Although the soil was kept at field capacity from the onset of the re-watering period, the final RWC of PB369 was not statistically different from that on the last day (day 6) of stress (Fig. 1F). The results also showed that the re-hydration of the leaf tissues upon re-watering was not related to specific patterns of variation in leaf RWC or water uptake during the water stress period. The 2-way ANOVA results showed that the effects of 'water treatment' and 'cultivar', and their interaction, were highly significant $(p<0.001)$. Multiple comparisons revealed that the leaf RWC of PB260 was significantly lower than that of all of the other cultivars on day 4 and 6, but not in the recovery period, suggesting high water uptake rates by this cultivar. On the contrary, PB369, with the highest RWC mean level on day 6 (65,2\%), was the only cultivar unable to re-hydrate by the end of the recovery period (Fig. 1).

An impairment of RWC recovery may be due to cellular damages or loss of stomatal regulation (Franks and Farquhar 2001). Marshall and Dumbroff (1999) reported that structural alterations, like those in cell wall elastic modulus, could lead to a delay in recovery. Failure of RWC to recover totally was also observed in maize by Kim et al. (2000) after a 12 d stress period.

\section{Gas-exchange}

Maximum values of net photosynthetic rate $(A)$ of unstressed plants ranged between 15 (PB 64, PB260 and PB369) and almost $30 \mu \mathrm{mol} \mathrm{CO} \mathrm{CO}^{-2} \mathrm{~s}^{-1}$ (PB269 and PB304), as shown in Fig. 2. Similar values were reported for maize grown under similar growth conditions (Maroco et al. 1998) and other $\mathrm{C}_{4}$ plants (Marques da Silva and Arrabaça 2004a).

In PB269, and particularly in PB260, A decreased gradually with increasing water deficit, reaching zero at RWC values below 40\% (Fig. 2C and 2D). A similar response by maize was reported by Lal and Edwards (1996). The other cultivars showed a sharp decrease in A over a narrow RWC range (100-80\% for AD3R and PB64 and 100-90\% for PB304 and PB369). To highlight the different responses, data points were grouped in two boxes (Fig. 2A, B, E, and F), or a trend line was fitted (Fig. 2C and D). Upon re-watering, the cultivars AD3R, PB64, PB269 PB304 recovered their initial water status but this was not so for PB260 and PB369 (Fig. 1). Except for cultivar PB64, the recovery of $A$ on re-watering was incomplete or absent in PB369 (Fig. 2, compare dotted boxes in each cultivar). The cultivar PB369 showed a unique phenotype in not fully recovering to the initial value of RWC and showing no recovery of $A$ after rewatering (Fig. 2F; Table I). 
Changes in intercellular $\mathrm{CO}_{2}$ partial pressure $\left(\mathrm{C}_{\mathrm{i}}\right)$ also differed among cultivars (Fig. 3). In general, $\mathrm{C}_{\mathrm{i}}$ tended to increase at higher water stress levels and recover to control values upon irrigation (Table I). However, in PB64 a transient $C_{i}$ rise before resuming its initial values was found (Fig. 3B), whereas in PB369 very high $C_{i}$ values were present during all the re-watering period (Fig. 3F). In both cultivars the highest $\mathrm{C}_{\mathrm{i}}$ values (Fig. 3B and 3F) were paralleled by the lowest $A$ values (Fig. 2B and 2F), pointing to non-stomatal inhibition of photosynthesis. In fact, nonstomatal limitations of $\mathrm{C}_{4}$ photosynthesis have already been reported by several authors (Loreto et al. 1995; Lal and Edwards 1996; Ghannoum et al. 2003; and Marques da Silva and Arrabaça 2004a). In PB64 both $A$ and $C_{i}$ recovered with increasing leaf RWC (Fig. 2B and 3B) but in PB369 $C_{i}$ remained high, with values above those in the gas used for measurement. The high $C_{i}$ was associated with negative values of $A$, and $A$ did not recover, suggesting irreversible damage to photosynthetic carbon metabolism and excessive respiration (Fig. 2F and 3F).

Decreases of $C_{i}$ during the early phases of water stress have been reported for maize (Lal and Edwards 1996), sugarcane (Du et al. 1996) and Setaria sphacelata (Marques da Silva and Arrabaça 2004a). Sharkey et al. (1990) argued that increased $C_{i}$ is an artefact due to patchy stomatal closure. However, several authors (Cheesman 1991; van Kraalingen 1990; Mott and Buckley 1998), using a more realistic normal model instead of the bimodal model of stomatal apertures, showed that the effect of patchiness on the estimation of $C_{i}$ was marginal.

The responses of $g_{s}$ to RWC reflected the response of $A$ (Fig. 4; Table I). As with $A$, $g_{s}$ was less sensitive to decreasing RWC in PB269 and particularly in PB260, than in the other cultivars. In PB260, $g_{s}$ fully recovered at the end of the re-watering period (Fig. 4C) but the leaf RWC did not (Fig. 1C). Differences in the control of the stomatal aperture during the water stress/recovery cycle could be associated with the different intrinsic water uses by the cultivars: PB269 had the highest values of $g_{s}$ under full-hydration (Fig. 4) but the lowest water uptake rate (data not shown), while PB260 was the cultivar with the highest water uptake rate (data not shown) and the highest $g_{s}$ during stress and recovery. The water balance phenotype of PB260 could depend on structural features such as a low cell wall elastic modulus, which would allow loss of more water while maintaining turgor but it could delay RWC recovery, as more water uptake is needed to reach full turgor, as reported by Marshall and Dumbroff (1999).

The cultivars that exhibited the type of response in $A$ shown in Figs. 2A, B, E and F showed similar trends in $\mathrm{g}_{\mathrm{s}}$ (solid boxes in Fig. 4A, B, E and F). However, the incomplete recovery of $A$ in AD3R and PB304 (Fig. 2A and 2E) could not be attributed to an incomplete recovery of $g_{s}$ (Fig. 4A and 4E), suggesting the presence of non-stomatal limitations during re-watering in these cultivars. In contrast, although $A$ and $C_{i}$ initial values were recovered in PB64, recovery of $g_{s}$ was not complete (Fig. 4B). In PB369, $g_{s}$ was maintained at very low stress values during all the rewatering period (Fig. 4F). This result, together with those for photosynthesis (Fig. 2F) and leaf RWC (Fig. 1E) exclude an explanation in terms of stress-induced loss of stomatal regulation of leaf water status, suggesting instead impairment in water uptake or in hydraulic conductance.

WUE decreased with increasing water deficit and, with the exception of PB269 and PB64, full recovery of initial control values was not observed after re-watering (Fig. 5). At the end of the recovery period the high WUE values observed in PB64 (Fig. 5B), together with low $g_{s}$ (Fig. 4B) and the high $A$ values reached for $C_{i}$ values, similar to those observed during stress (Fig. 3B), suggest that in this cultivar the photosynthetic affinity for carbon might increase after a water stress period. This is consistent with the finding that the maximal and the physiological activity of phosphoenolpyruvate carboxylase under water stress can increase 3-fold (Marques da Silva and Arrabaça 2004b).

In fully hydrated leaves, the highest WUE was found in AD3R and the lowest in PB260. However, in PB260 WUE was maintained under moderate to severe stress conditions and decreased only at RWC values below $40 \%$ (Fig. 5C) while AD3R showed a dramatic drop in WUE at moderate stress (Fig. 5A). This was due to severe effects on $A$ that were not overcome during re-watering (Fig. 2A), highlighting the importance of biochemical limitations in this cultivar. 
In contrast, the gas-exchange phenotype of PB260 suggested that it would have an advantage under stress conditions but not in well-watered soils, especially after periods of water stress (Fig. 5C).

\section{Modulated Chl a fluorescence}

The variation of the area above the fluorescence rise curve normalized by the variable fluorescence $\left(S_{m}\right)$ (Strasser et al. 2004) allows an estimate of the size of the functional quinone pool (Lazár 1999), i.e., the quantity of electrons necessary to fully reduce it (Joliot and Joliot 2002). This parameter was estimated through the stress and recovery cycle to evaluate effects on photochemical machinery (Fig. 6; Table I). It was observed that $S_{m}$ decreased with decreasing RWC. The decrease was greatest in cultivars AD3R and PB304. As for gas-exchange parameters, the highest values during the stress period were maintained in PB260, showing a major decrease only in severe stress (Fig. 6C). Full recovery to the initial $S_{m}$ values after re-watering was observed in all cultivars except AD3R. The incomplete recovery of the functional quinone pool may account for the deficient recovery of photosynthesis found in this cultivar (Fig. 2A and 3A). In PB64, the $\mathrm{S}_{\mathrm{m}}$ values after re-watering were on average higher than those observed during the early phases of the drought treatment (Fig. 6B), supporting the previous idea that photosynthetic efficiency was improved in this cultivar after the water stress period. It must be stressed, however, that this approach gives only a rough estimate of the functional quinone pool, as the final phase (the transition from I to P) may represent a filling up of the ferredoxin pool at the acceptor side of PSI. Nonetheless these data are consistent with the results obtained with the gas-exchange approach in the sense that: PB260 is probably the most drought tolerant cultivar with high performances under stress conditions; AD3R seems to be more prone to metabolic limitations, showing a limited recuperation of the photosynthetic function upon irrigation; an investment on the photosynthetic electron transport components seems to occur in PB64 after re-watering, contributing to overcome negative effects imposed during the water stress period. and PB369 is the most susceptible cultivar to the regime of water stress studied.

The maximum quantum efficiency of PSII $\left(\mathrm{F}_{\mathrm{v}} / \mathrm{F}_{\mathrm{m}}\right)$ ranged between 0.7 and 0.8 at near full hydration (Fig. 7; Table I), which is close to values reported for most plant species in the absence of stress conditions (Maxwell and Johnson 2000). With decreasing RWC, this parameter dropped to ca. 0.6 except in AD3R and PB304 where lower $F_{v} / F_{m}$ values were registered. In AD3R, the $F_{v} / F_{m}$ value fell to near 0.4 in the RWC range of 50-70\% (mild stress) (Fig. 7A), and in PB304 a value of below 0.3 was reached at RWC of 40\% (severe stress) for one replicate (Fig. 7E). These low values were probably due to a greater degradation rate of PSII reaction centers (van Wijk et al. 1994) and/or to a lower reparation rate of D1 protein (Nishiyama et al. 2006), which would be in agreement with the resilience observed for $A, \mathrm{C}_{\mathrm{i}}, \mathrm{S}_{\mathrm{m}}$ and $\mathrm{F}_{\mathrm{v}} / \mathrm{F}_{\mathrm{m}}$ in the cultivar AD3R (Fig. 2A, 3A, 6A and 7A).

The $\mathrm{F}_{\mathrm{v}} / \mathrm{F}_{\mathrm{m}}$ is generally considered a parameter very resistant to stress conditions. Marques da Silva and Arrabaça (2004a) found that in S. sphacelata it remained unchanged when leaf RWC decreased to 50\%, and Zhao et al. (2007) found significant reductions only at very high salt stress in two oat genotypes. Although less sensitive than other measured variables, an unexpected diversity of responses was found among the maize cultivars: $F_{v} / F_{m}$ was extraordinarily resistant in PB260 and very sensitive in AD3R. As this parameter is related to the functioning of the core PSII reaction centre (i.e., a measure of the maximal potential photochemical efficiency of PSII), it appears that there are marked differences concerning its function and susceptibility to photoinhibition amongst the maize varieties.

The initial values of the photochemical quenching coefficient (qP) were higher in AD3R, PB304 and PB369 (> 0.7) and lower in PB64 and PB269 (<0.6) (Fig. 8). With decreasing RWC a decrease of qP was also observed denoting an increase in the reduction state of the plastoquinone (PQ) pool (Maxwell and Johnson 2000), and the use of a lower fraction of the energy for photochemistry. Globally these results are in accordance with those concerning the size of the 
functional PQ pool (Fig. 6). The decrease in qP was highest in PB304, and in PB260 qP values were maintained during most of the stress period decreasing slightly only at RWC below 50\% (Fig. 8C). After irrigation, qP recovered close to the initial values in all cultivars (Fig. 8; Table I). During the water stress treatment a statistically significant correlation between non-photochemical quenching coefficient (qN) and RWC could be found only for PB304 (Fig. 9E), although increased qN values at the end of the stress period were also observed in AD3R, PB369 and PB260. In this cultivar, qN increased only at RWC below 50\% (Fig. 9C), and in PB269 qN fluctuated randomly (Fig. 9D). The tendency for qN to increase with decreasing RWC suggests that, PSII reaction centers can be protected from excess excitation energy in all varieties except B269, by partially dissipating it through non-photochemical mechanisms. After re-watering, qP returned close to the initial values in all cultivars. The steep increase in qP with decreased RWC for PB304 (Fig. 9E) might explain why this cultivar, unlike AD3R - a cultivar with a similar water stress/recovery phenotype - was more protected from metabolic impairment of the photochemical apparatus (Fig. 3A, 3E, 6A and 6E).

The values obtained for the electron transport rate in PSII (ETR) are in the range obtained for corn hybrids under adequate and water deficit conditions in a field study (O’Neill et al. 2006). In AD3R and PB304 there was a sharp decrease of ETR during the stress period, while in the other cultivars the decrease was less pronounced (Fig. 10; Table I). This result is consistent with those for $A$ (Fig. 2), $S_{m}$ (Fig 6) and $F_{v} / F_{m}$ (Fig. 7). After re-watering, ETR recovered to above the initial values in PB64 and PB269 (Fig. 10B and 10D. There was little change in ETR in PB269 and a decrease only at RWC below 50\%, in PB260 so that ETR levels were maintained at moderate stress as for other tolerant lines (O’Neil et al. 2006). The relatively high values of ETR observed in PB369, even during stress (as well as the other parameters concerning PSII activity but mainly $\mathrm{F}_{\mathrm{v}} / \mathrm{F}_{\mathrm{m}}$ ), seem to contradict the results obtained by gasexchange measurements. One possible explanation is that the limitations imposed on photosynthesis by water stress were more on $\mathrm{C}$ metabolism than on the photochemical components, leaving the photochemical apparatus relatively free from damage, eventually protected by dissipative mechanisms like the Mehler reaction or plastid terminal oxidase (PTOX) activity that could act as electron quenchers.

The results from chlorophyll $a$ fluorometry and gas-exchange measurements were generally consistent with the measurements of gas exchange in distinguishing tolerant from susceptible cultivars, confirming the potential of chlorophyll fluorescence to assess photosynthetic performance (Earl and Tollenaar 1999). However, they also revealed that some susceptible phenotypes may not be identified by this method (the case of PB369).

Under drought stress plants can undergo acclimation processes, allowing the onset of water stress tolerance mechanisms, by changes to metabolism (Marques da Silva and Arrabaça 2004c), morpho-physiological and developmental characteristics. In all cultivars, a decrease in RWC led to a decrease in gas-exchange related parameters ( $A, \mathrm{~g}_{\mathrm{s}}, \mathrm{WUE}$ ), a typical response to this type of stress (Turner 1974). However, cultivar-specific differences were found both under stress and after re-watering. The cultivars PB260 and PB269 showed a gradual decrease of $A$ and $g_{s}$ with RWC, whereas the other varieties were sensitive to even moderate water deficit. PB269 showed the highest $A$ value in irrigated plants and PB260 showed the lowest values of $A$ but the highest WUE under stress conditions. Although PB260 exhibited low A values under conditions of full water supply, it is possible that the overall C assimilation may be compensated by the maintenance of higher $A$ values during stress periods (Fig. 2C). Accordingly, only in PB260 and PB269 were high levels of ETR and $\mathrm{F}_{\mathrm{v}} / \mathrm{F}_{\mathrm{m}}$ maintained at low RWC.

Differences in recovery from stress were even greater. To focus just on $A$ and RWC variations, they both recovered in two cultivars (PB64 and PB269), only RWC but not $A$ in two others (AD3R and PB304), $A$ but not RWC recovered in PB260, and finally, neither A nor RWC recovered in PB369. Therefore, it seems inappropriate to classify the cultivars by main broad categories, but rather to acknowledge that each one may exhibit specific traits, or set of traits, of adaptive value when facing water stress. Of the six cultivars analyzed, PB260 and PB269 stood out as cultivars 
with greater tolerance to water stress and PB369 as the least tolerant to water stress. PB260 exhibited a good performance through moderate to severe stress, enduring low leaf RWC but didn't regain initial RWC or WUE. Although not so effectively under moderate stress, PB269 also maintained high A, ETR and gs values but, unlike PB260, regained initial WUE and RWC. PB260, and to a lesser extent PB269, were able to adapt gas exchange parameters, namely the net photosynthetic rate and stomatal conductance, to the decrease of leaf RWC maintaining high values of photochemical efficiency (e.g. $S_{m}, F_{v} / F_{m}, E T R$ ) at low RWC. PB260 can endure better water stress periods while maintaining high rates of photosynthesis and productivity, possibly through a water accumulation/water use specific strategy, and PB269 can endure better cycles of water scarcity/water availability, avoiding excessive water losses under well-watered conditions, through a more conservative regulation of $\mathrm{g}_{\mathrm{s}}$. The cultivars that were more sensitive to water deficit exhibited different behaviours and other interesting traits: PB64 revealed the ability to overcome stress effects by increasing the efficiency of photochemical machinery and C metabolism after episodes of water deficit, and PB304 exhibited high efficiencies in non-photochemical quenching of excess energy, protecting reaction centres from overload under low leaf RWC. At the other extreme of the tolerance range, there’s PB369. This cultivar was unable to activate acclimation mechanisms, and hence to avoid damaging events at relatively high RWC values, presumably due to hydraulic, metabolic and structural impairments.

The variability of strategies shown in the six cultivars is in agreement with the diversity of responses reported for $\mathrm{C}_{4}$ plants in the literature. According to Ghannoum (2009) the differences found in stomatal and non-stomatal contributions to the limitation of photosynthesis could be due, at least in part, to the species-specific differences. We herein present strong evidences for true inter-varietal differences in stomatal and non-stomatal limitations of photosynthesis in water stressed plants. This work also showed that there is a relatively wide basis of physiological heterosis in maize that can be explored for crop improvement. In fact, although future confirmation is needed at the field level, the data reveal a wide physiological plasticity to deal with water stress. This is of utmost scientific and social relevance regarding not only higher future food needs due to the increasing world population, but also the urgent improvement of food crops water use efficiency in order to endure severe and/or erratic water limitations in some geographic regions of the globe.

\section{Acknowledgements}

The authors are in debt to Banco Português de Germoplasma Vegetal for providing the homozygous maize lines and to Professor Pedro Fevereiro (FCUL/ITQB, Portugal) for assistance on the selection of the cultivars to be studied. We want to express our deep gratitude to Doctor Alfred Keys (Rothamsted Research, U.K.) to the comprehensive revision of the style and grammar and the many suggestions for improving the manuscript.

\section{References}

Asner GP, Nepstad D, Cardinot G, Ray D (2004) Drought stress and carbon uptake in an Amazon forest measured with spaceborne imaging spectroscopy. P Natl Acad Sci USA 101:6039-6044

Beerling D (2007) The Emerald Planet: How Plants Changed Earth’s History. Oxford University Press: New York, p. 288

Bruce WB, Edmeades GO, Barker TC (2002) Molecular and physiological approaches to maize improvement for drought tolerance. J Exp Bot 53:13-25

Burghardt M, Riederer M (2003) Ecophysiological relevance of cuticular transpiration of deciduous and evergreen plants in relation to stomatal closure and leaf water potential. J Exp Bot 54:1941-1949 
Carmo-Silva A, Soares A, Marques da Silva J, Bernardes da Silva A, Keys A, Arrabaça MC (2007) Photosynthetic responses of three C4 grasses of different metabolic sub-types to water deficit. Funct Plant Biol 34:204-213

Catsky J (1960) Determination of water deficit in discs cut out from leaf blades. Biol Plantarum 2:76-77

Chaves MM, Pereira JS, Maroco J, Rodrigues ML, Ricardo CPP, Osório ML, Carvalho I, Faria T, Pinheiro C (2002) How plants cope with water stress in the field. Photosynthesis and growth. Ann Bot 89:907-916

Cheesman J (1991) Patchy: simulating and visualizing the effects of stomatal patchiness on photosynthetic $\mathrm{CO}_{2}$ exchange studies. Plant Cell Environ 14:593-599

Cornic G, Fresneau C (2002) Photosynthetic carbon reduction and carbon oxidation cycles are the main electron sinks for photosystem II activity during mild drought. Ann Bot 89:887-894

Du YC, Kawamitsu Y, Nose A, Hiyane S, Muarayama S, Muraya S, Wasano K, Uchida Y (1996) Effects of water stress on carbon exchange rate and activities of photosynthetic enzyme in leaves of sugarcane (Saccharum sp.). Funct Plant Biol 23:719-726

Earl HJ, Tollenaar M (1999) Using chlorophyll fluorometry to compare photosynthetic performance of commercial maize (Zea mays L.) hybrids in the field. Field Crops Res 61:201-210

Edwards EJ, Still CJ (2008) Climate, phylogeny and the ecological distribution of $\mathrm{C}_{4}$ grasses. Ecol Lett 11:266-276

Franks PJ, Farquhar GD (2001) The effect of exogenous abscisic acid on stomatal development, stomatal mechanics, and leaf gas exchange in Tradescantia virginiana. Plant Physiol 125:935-942

Genty B, Briantais J-M, Baker NR (1989) The relationship between the quantum yield of photosynthetic electron transport and quenching of chlorophyll fluorescence. Biochim Biophys Acta 990:87-92

Ghannoum O (2009) $C_{4}$ Photosynthesis and water stress. Ann Bot 103:635-644

Ghannoum O, von Caemmerer S, Conroy JP (2002) The effect of drought on plant water use efficiency of 9 NADME and 9 NADP-ME $C_{4}$ grasses. Funct Plant Biol 29:1337-1348

Ghannoum O, Conroy JP, Driscoll SP, Paul MJ, Foyer CH, Lawlor DW (2003) Non-stomatal limitations are responsible for drought-induced photosynthetic inhibition in four $\mathrm{C}_{4}$ grasses. New Phytol 159:835-844

Hadi G (2007) Advances in maize breeding through the cumulative complex improvement of sources. Cereal Res Commun 35:1519-1526

Hare PD, Cress WA, van Staden J (1999) Proline synthesis and degradation: a model system for elucidating stressrelated signal transduction. J Exp Bot 50:413-434

Jacobs BF, Kingston JD, Jacobs LL (1999) The origin of grass-dominated ecosystems. Ann. Mo. Bot. Gard. 86:590-643

Joliot P, Joliot A (2002) Cyclic electron transport in plant leaf. P Natl Acad Sci USA 99:10209-10214

Kellogg EA (2001) Evolutionary history of grasses. Plant Physiol 125:1198-1205

Kim J-Y, Mahé A, Brangeon J, Prioul J-L (2000) A maize vacuolar invertase, IVR2, is induced by water stress. Organ/tissue specificity and diurnal modulation of expression. Plant Physiol 124:71-84

Lal A, Edwards GE (1996) Analysis of inhibition of photosynthesis under water stress in the $\mathrm{C}_{4}$ species Amaranthus creuntus and Zea mays: Electron transport, $\mathrm{CO}_{2}$ fixation and carboxylation capacity. Aust J Plant Physiol 23:403-412

Lazár D (1999) Chlorophyll a fluorescence induction. Biochim Biophys Acta 1412:1-28

Long SP, Hallgren J-E (1985) Measurements of $\mathrm{CO}_{2}$ assimilation by plants in field and laboratory. In: J Coombs, DO Hall, SP Long, JMO Scurlock (eds). Techniques in bioproductivity and photosynthesis. Pergamon Press: New York, p. 62-94

Long SP, Hallgren J-E (1993) Measurements of $\mathrm{CO}_{2}$ assimilation by plants in field and laboratory. In: DO Hall, 
JMO Scurlock, HR Bolhar-Nordenkampf, RC Leegood, SP Long (eds). Photosynthesis and production in a changing environment - a field and laboratory manual. Chapman \& Hall: London, p. 129-167

Loreto F, Tricoli D, Di Marco G (1995) On the relationship between electron transport rate and photosynthesis in leaves of the $\mathrm{C}_{4}$ plant Sorghum bicolor exposed to water stress, temperature changes and carbon metabolism inhibition. Aust J Plant Physiol 22:885-892

Maroco J, Ku M, Lea P, Dever L, Leegood R, Furbank R, Edwards G (1998) Oxygen requirement and inhibition of $\mathrm{C}_{4}$ photosynthesis - An analysis of $\mathrm{C}_{4}$ plants deficient in the $\mathrm{C}_{3}$ and the $\mathrm{C}_{4}$ cycles. Plant Physiol 116:823-832

Marques da Silva J, Arrabaça MC (2004a) Photosynthesis in the water-stressed $\mathrm{C}_{4}$ grass Setaria sphacelata is mainly limited by stomata with both rapidly and slowly imposed water deficits. Physiol Plantarum 121:409-420

Marques da Silva J, Arrabaça MC (2004b) Photosynthetic enzymes of the C4 gramineae Setaria sphacelata under water stress: a comparison between rapidly and slowly imposed water deficit. Photosynthetica 42:43-47

Marques da Silva J, Arrabaça MC (2004c) Contributions of soluble carbohydrates to the osmotic adjustment in the $\mathrm{C}_{4}$ grass Setaria sphacelata: A comparison between rapidly and slowly imposed water stress. J Plant Physiol 161:551-555

Marshall JG, Dumbroff EB (1999) Turgor regulation via cell wall adjustment in white spruce. Plant Physiol 119:313-319

Maxwell K, Johnson GN (2000) Chlorophyll fluorescence - A practical guide. J Exp Bot 51:659-668

Mott KA, Buckley TN (1998) Stomatal heterogeneity. J Exp Bot 49:407-417

Nayyar H (2003) Accumulation of osmolytes and osmotic adjustment in water-stressed wheat (Triticum aestivum) and maize (Zea mays) as affected by calcium and its antagonists. Environ Exp Bot 50:253-264

Nishiyama Y, Allakverdiev SI, Murata N (2006) A new paradigm for the action of reactive oxygen species in the photoinhibition of photosystem II. Biochim Biophys Acta 1157:742-749

O'Neill PM, Shanahan JF, Schepers JS (2006) Use of chlorophyll fluorescence assessments to differentiate corn hybrid response to variable water conditions. Crop Sci 46:681-687

Pêgo S (1997) Resistance or tolerance? Philosophy may be the answer. In: S Pêgo, R Martins (eds.). Proc. XIX Conf. of the Internat. Working Group on Ostrinia nubilalis and other maize pests, pp. 303-341. Guimarães, Portugal

Pospíšilová J (2003) Participation of phytohormones in the stomatal regulation of gas exchange during water stress. Biol Plantarum 46:491-506

Schansker G, Tóth S, Strasser R (2005) Methylviologen and dibromothymoquinone treatments of pea leaves reveal the role of photosystem I in the Chl a fluorescence rise OJIP. Biochim Biophys Acta 1706:250-261

Schreiber U, Schliwa U, Bilger W (1986) Continuous recording of photochemical and non-photochemical fluorescence quenching with a new type of modulation fluorometer. Photosynth Res 10:51-62

Sharkey T, Loreto F, Vassey TL (1990) Effects of stress on photosynthesis. In: M Baltscheffsky (ed.). Current Research in Photosynthesis, vol. IV. Kluwer Academic Publishers, Dordrecht, p. 549-556

Sharp RE, LeNoble ME (2002) ABA, ethylene and the control of shoot and root growth under water stress. J Exp Bot 53:33-37

Sharp RE, Poroyko V, Hejlek LG, Spollen WG, Springer GK, Bohnert HJ, Nguyen HT (2004) Root growth maintenance during water deficits: physiology to functional genomics. J Exp Bot 55:2343-2351

Siddique MRB, Hamid A, Islam MS (1999) Drought stress effects on photosynthetic rate and leaf gas exchange of wheat. Bot Bull Acad Sinica 40:141-145

Still CJ, Berry JA, Collatz GJ, DeFries RS (2003) Global distribution of C3 and C4 vegetation: Carbon cycle 
implications. Global Biogeochem Cycles 17:6.1-6.14

Strasser RJ, Tsimili-Michael M, Srivastava A (2004) Analysis of the chlorophyll a fluorescence transient. In: GC Papageorgiou, Govindjee (eds.). Chlorophyll a fluorescence: A signature of photosynthesis. Springer: Dordrecht, p. 321-362

Turner NC (1974) Stomatal behaviour and water status of maize, sorghum, and tobacco under field conditions: II. At low soil water potential. Plant Physiol 53:360-365

van Kraalingen D (1990) Implications of non-uniform stomatal closure on gas exchange calculation. Plant Cell Environ 13:1001-1004

van Wijk KJ, Nilsson LO, Styring S (1994) Synthesis of reaction center proteins and reactivation of redox components during repair of photosystem II after light-induced inactivation. J Biol Chem 269:28382-28392

Vaz Patto MC, Satovic Z, Pêgo S, Fevereiro P (2004) Assessing the genetic diversity of Portuguese maize germplasm using microsatellite markers. Euphytica 137:63-72

von Caemmerer S, Farquhar GD (1981) Some relationships between the biochemistry and the gas exchange of leaves. Planta 153:376-387

Yordanov I, Velikova V, Tsonev T (2003) Plant responses to drought and stress tolerance. Bulg J Plant Physiol Special Issue:187-206

Zhao GQ, Ma BL, Ren CZ (2007) Growth, gas exchange, chlorophyll fluorescence, and ion content of naked oat in response to salinity. Crop Sci 47:123-131 


\section{Figure and Table Captions}

Fig. 1. Relative water content (RWC) of leaves during the period without watering (black columns) and during rewatering (grey columns) for six maize cultivars. Columns represent mean values $(n=4-5)$ and the respective standard deviation (SD) bars are shown on top. Statistical notation: for each cultivar, RWC mean values with different letters were significantly different $(p<0.05)$.

Fig. 2. Net photosynthetic rate $(A)$ as a function of leaf relative water content (RWC), during the period without watering $(\Delta)$ and during re-watering $(\boldsymbol{\nabla})$, in the six maize cultivars. All replicates were plotted $(28<\mathrm{n}<35)$ and values recorded at the lowest RWC (day 6) are simultaneously the last of the stress period and the first of the recovery period. Whenever linear and non-linear regressions were significant, the derived equations, the respective correlation coefficient and $p$ values are shown. Solid boxes draw attention to the sensitive type response: a sharp decline during water stress (upright rectangles), and low values obtained at the end of stress period or also during recovery (horizontal rectangles). Dotted boxes highlight that stress and recovery values were different.

Fig. 3. Partial pressure of $\mathrm{CO}_{2}$ in the intercellular space $\left(\mathrm{C}_{\mathrm{i}}\right)$ as a function of leaf relative water content (RWC), during the period without watering $(\Delta)$ and during re-watering $(\boldsymbol{\nabla})$, in the six maize cultivars. Plotting and graphic options are the same as in Fig. 2.

Fig. 4. Stomatal conductance $\left(\mathrm{g}_{\mathrm{s}}\right)$ as a function of leaf relative water content (RWC), during the period without watering $(\Delta)$ and during re-watering $(\boldsymbol{\nabla})$ in the six maize cultivars. Plotting and graphic options are the same as in Fig. 2.

Fig. 5. Water use efficiency (WUE) as a function of leaf relative water content (RWC), during the period without watering $(\Delta)$ and during re-watering $(\boldsymbol{\nabla})$, in the six maize cultivars. Plotting and graphic options are the same as in Fig. 2. The arrow indicates the approximated RWC level below which WUE varied significantly.

Fig. 6. Variation of the normalized complementary area of the fast phase of Kautsky's curve $\left(S_{m}\right)$ as a function of leaf relative water content (RWC), during the period without watering $(\Delta)$ and during re-watering ( $\boldsymbol{\nabla}$ ), in the six maize cultivars. Plotting and graphic options are the same as in Fig. 2. The arrow indicates the approximated RWC level below which $\mathrm{S}_{\mathrm{m}}$ varied significantly.

Fig. 7. Maximum quantum yield of PSII $\left(F_{v} / F_{m}\right)$ as a function of leaf relative water content (RWC), during the period without watering $(\Delta)$ and during re-watering $(\boldsymbol{\nabla})$, in the six maize cultivars. Plotting and graphic options are the same as in Fig. 2. The arrows indicate the approximated RWC levels below which $\mathrm{F}_{\mathrm{v}} / \mathrm{F}_{\mathrm{m}}$ varied significantly.

Fig. 8. Photochemical quenching coefficient (qP) as a function of leaf relative water content (RWC), during the period without watering $(\Delta)$ and during re-watering $(\boldsymbol{\nabla})$, in the six maize cultivars. Plotting and graphic options are the same as in Fig. 2. The arrow indicates the approximated RWC level below which qP varied significantly. 
Fig. 9. Non-photochemical quenching coefficient (qN) as a function of leaf relative water content (RWC), during the period without watering $(\Delta)$ and during re-watering $(\boldsymbol{\nabla})$, in the six maize cultivars. Plotting and graphic options are the same as in Fig. 2. The arrow indicates the approximated RWC level below which qN varied significantly.

Fig. 10. Electron transport rate (ETR) as a function of leaf relative water content (RWC), during the period without watering $(\Delta)$ and during re-watering $(\boldsymbol{\nabla})$, in the six maize cultivars. Plotting and graphic options are the same as in Fig. 2. The arrow indicates the approximated RWC level below which ETR varied significantly.

Table I. Summary of the variation of the physiological parameters with RWC 

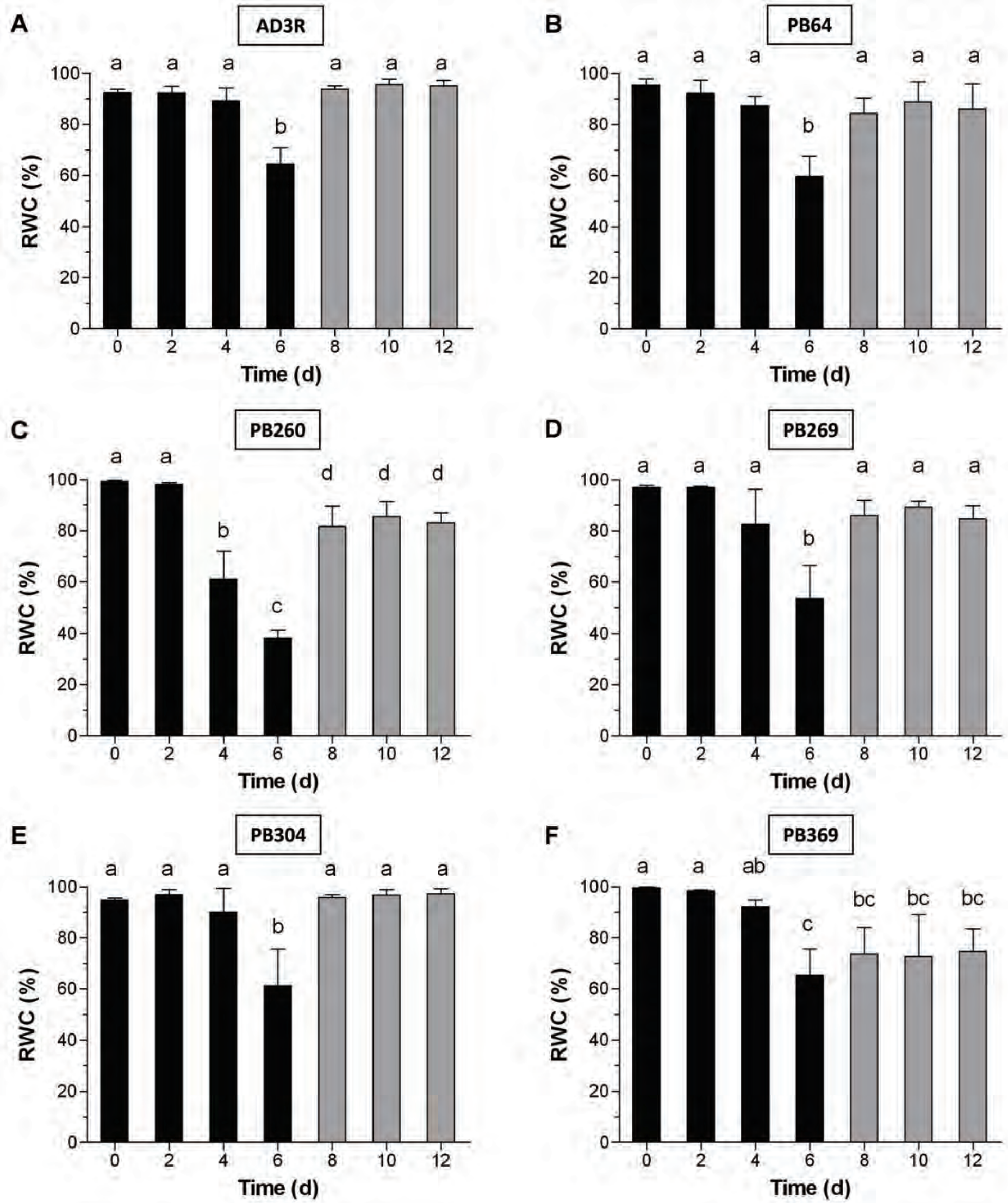

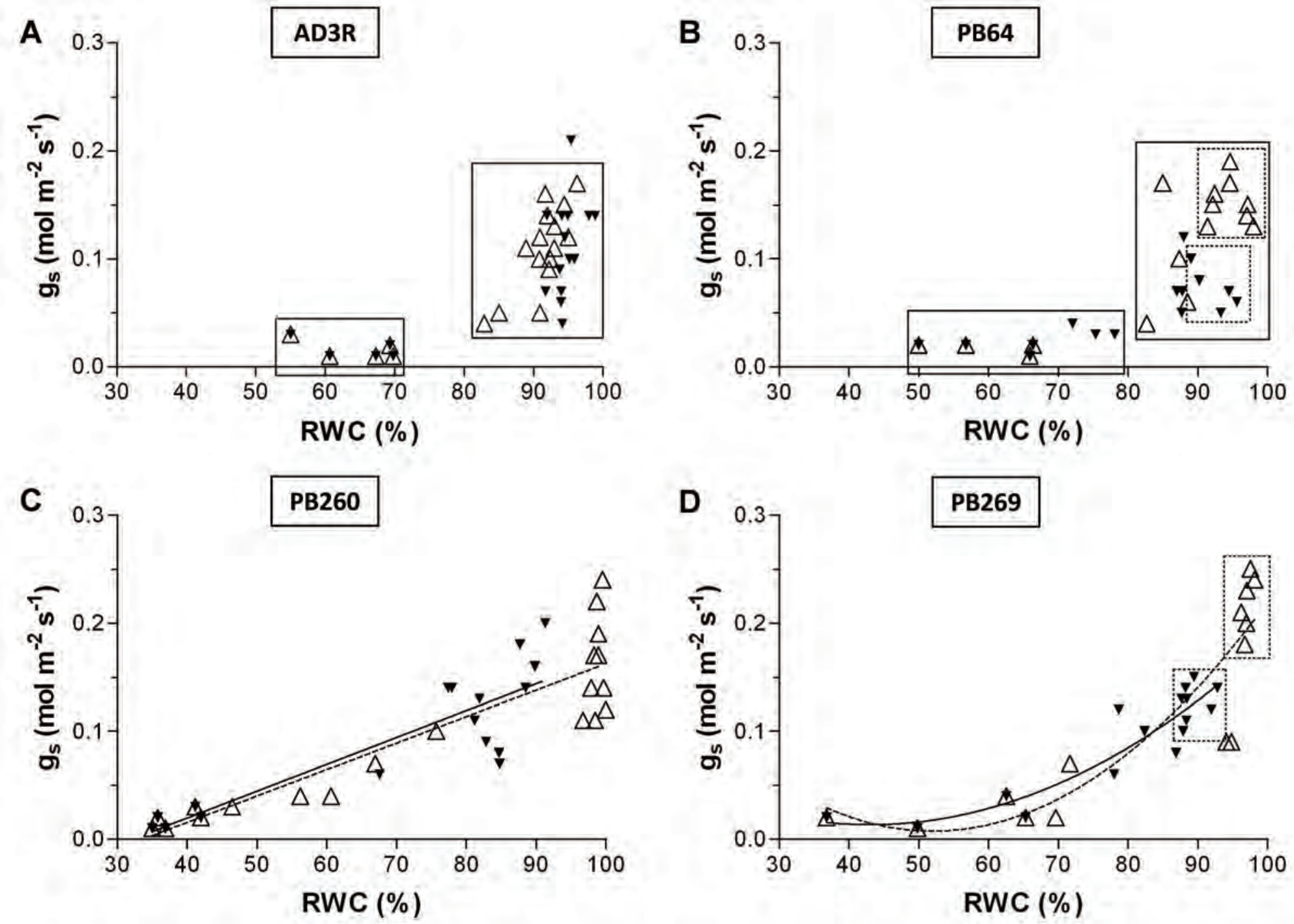

Stress $(--): y=-0.08262+0.002449 x(r=0.90 ; p<0.01)$

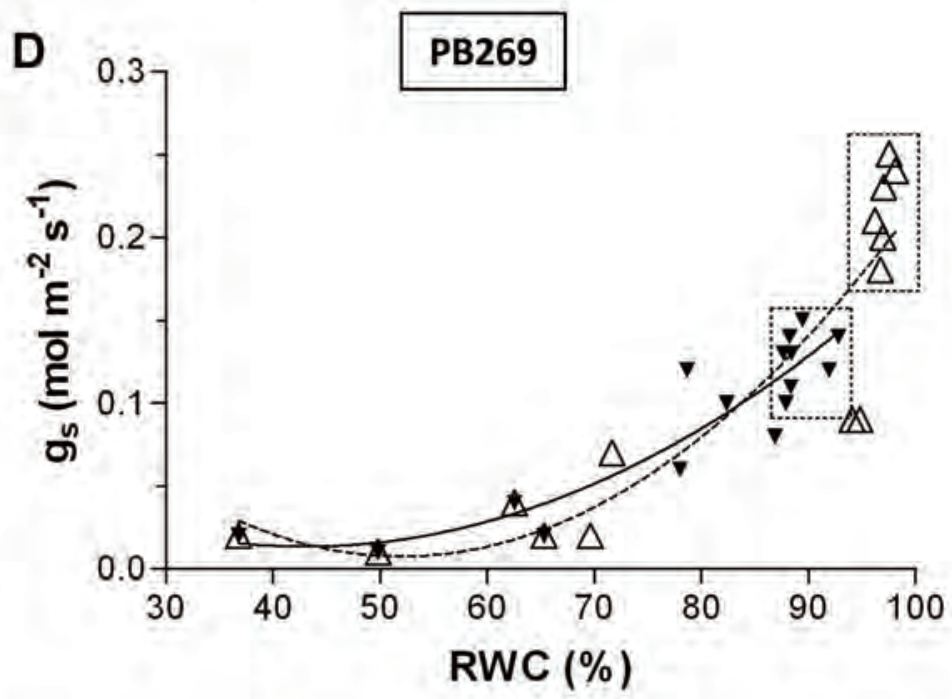

Recovery $(-): y=-0.07998+0.002487 x(r=0.87 ; p<0.01)$

E

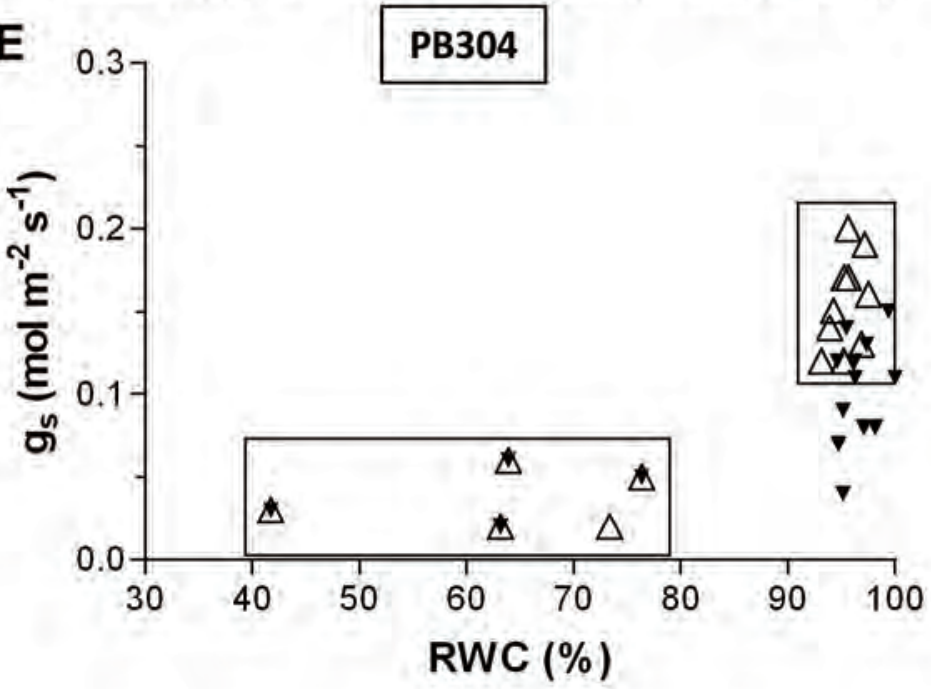

Stress (- $): y=0.2576-0.009618 x+9.241 e^{-5} x^{2}(r=0.90 ; p<0.05)$ Recovery $(-): y=0.1093-0.00447 x+5.204 e^{-5} x^{2}(r=0.91 ; p<0.05)$

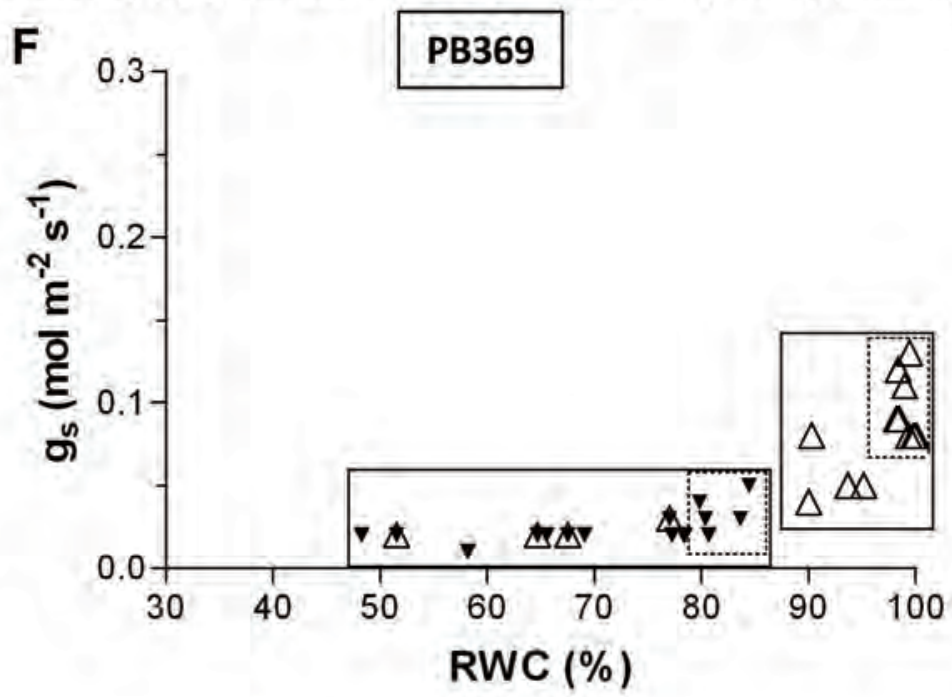



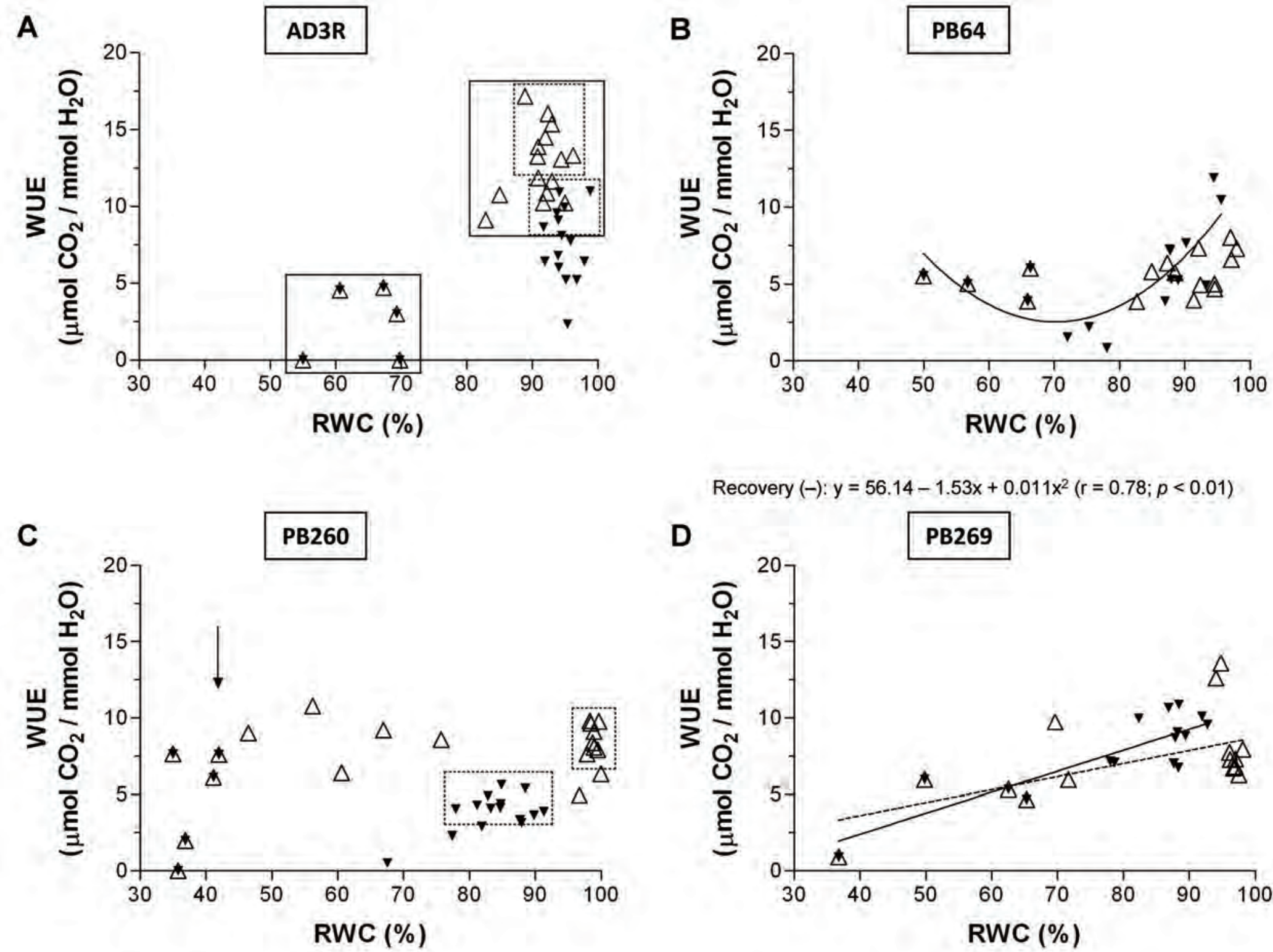

E

\section{PB304}
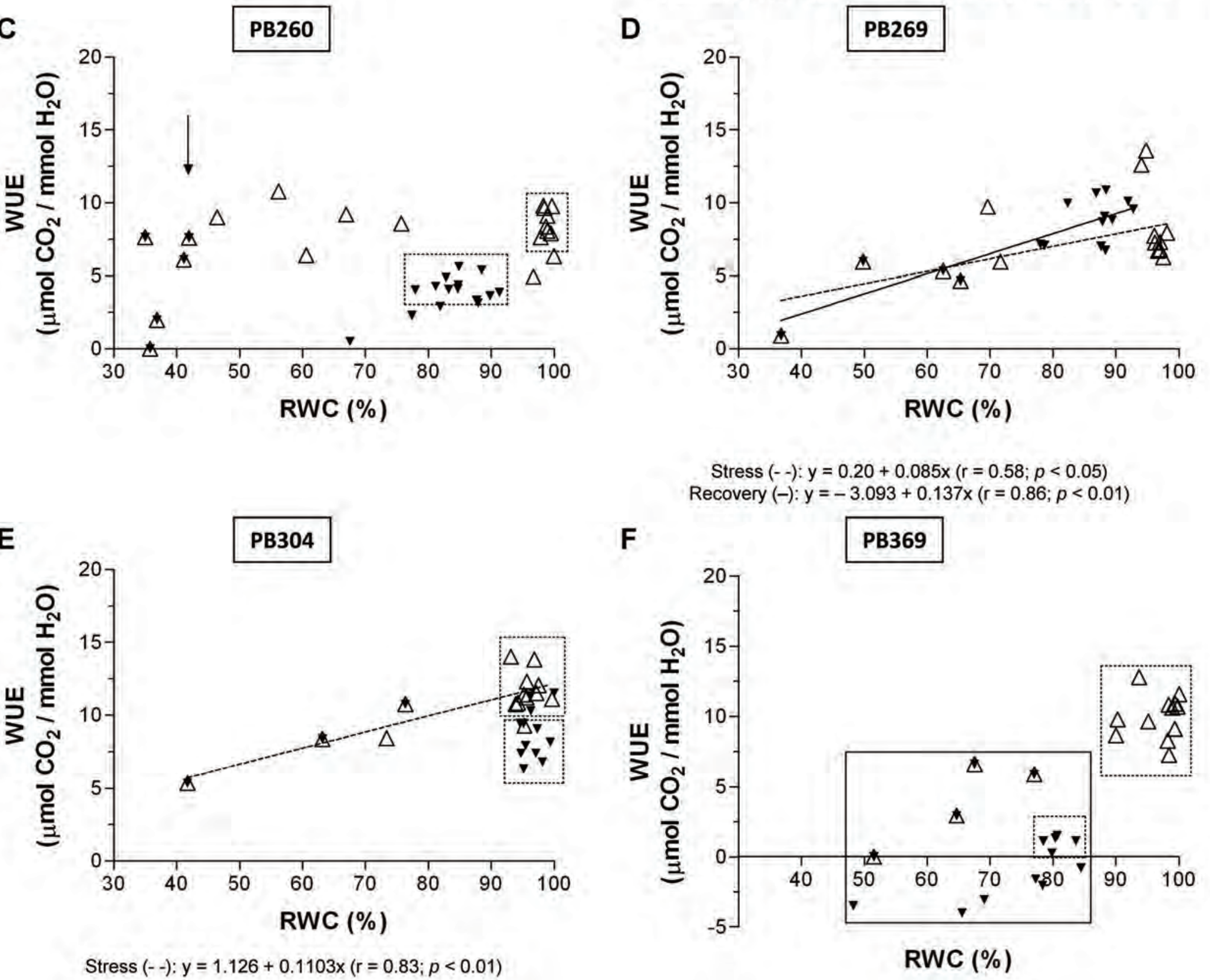


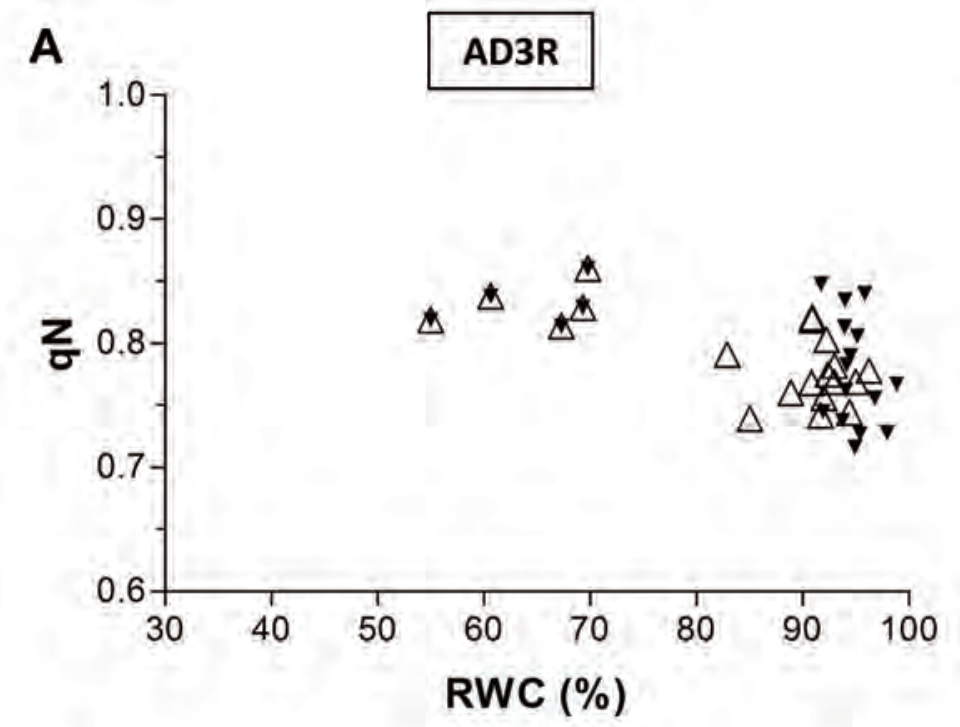

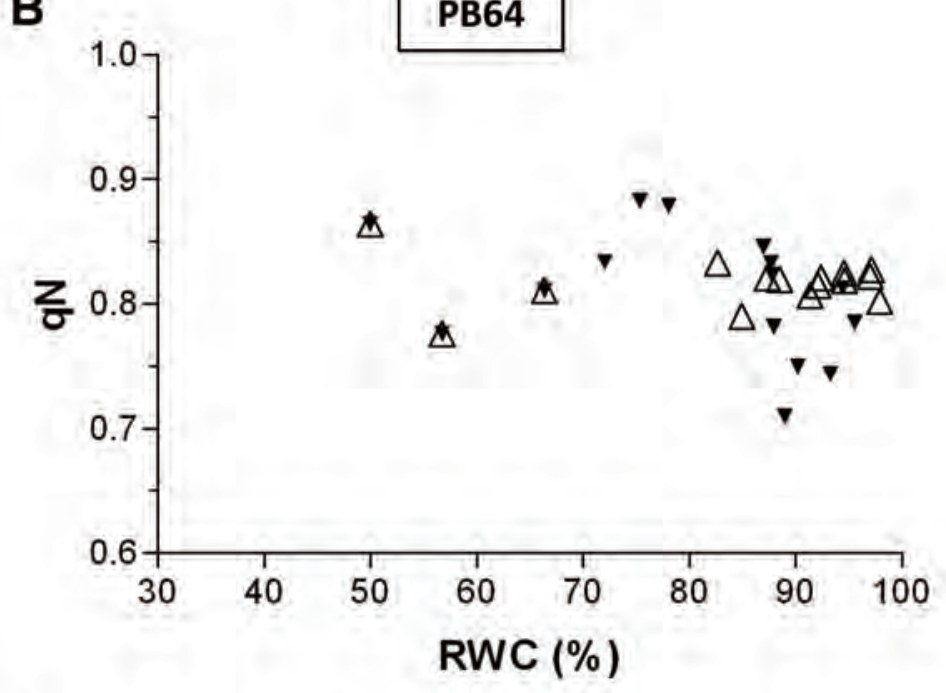

D

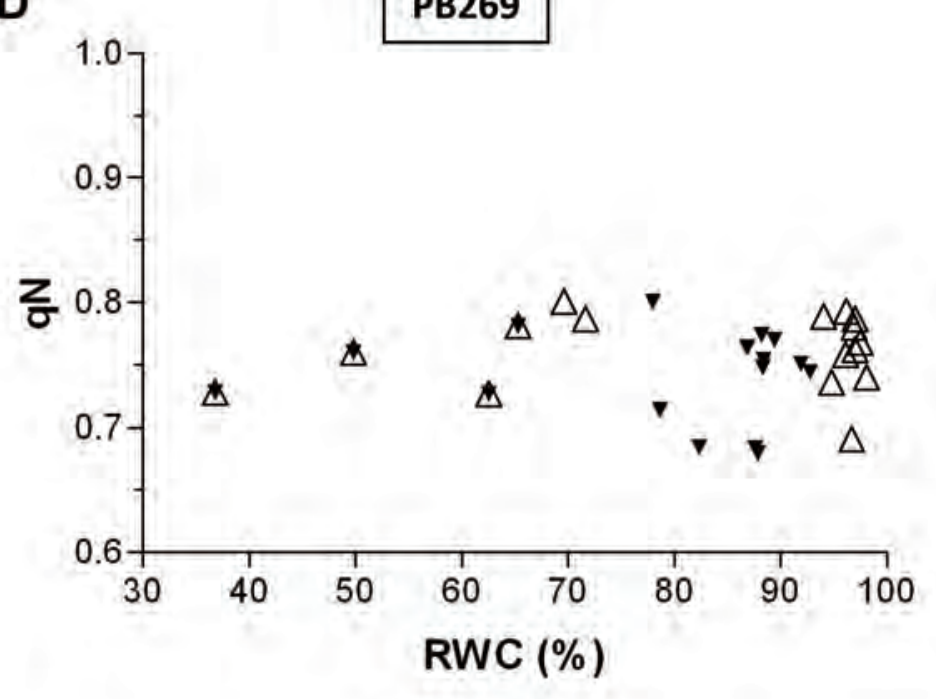

F

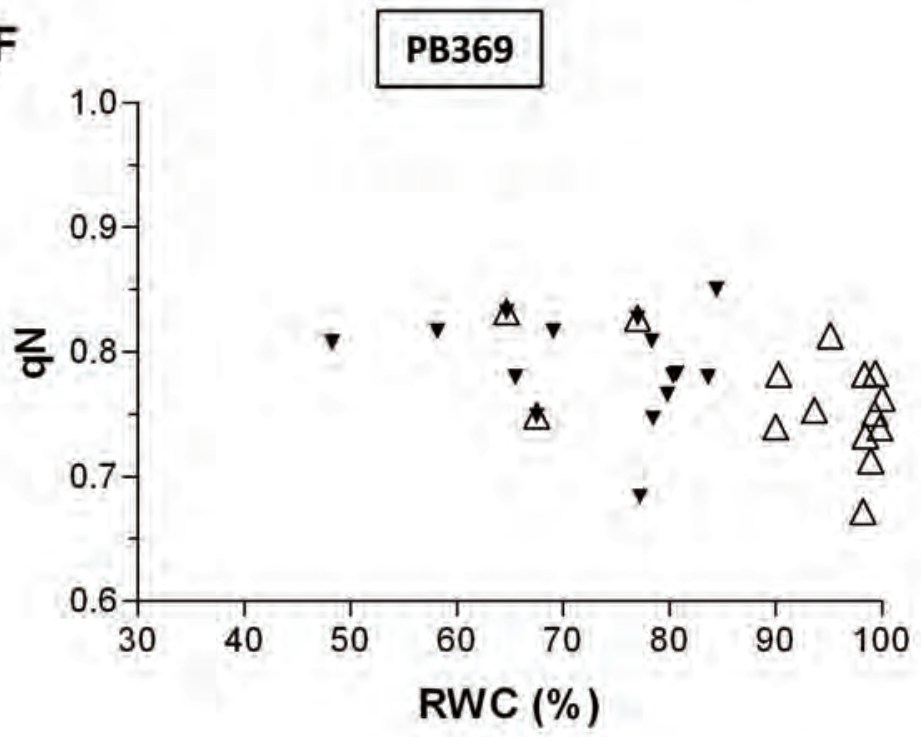




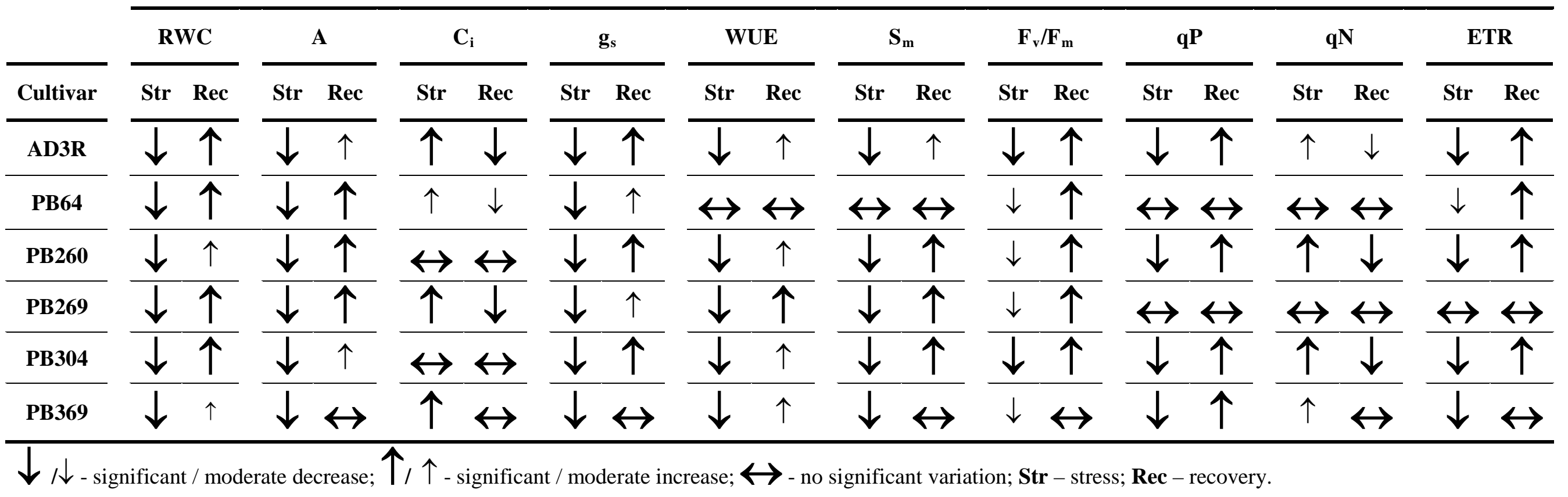

